ISSN: 0213-2079 - ISSN electrónico: 2386-3889

DOI: http://dx.doi.org/10.14201/shhmo20163812338

\title{
SAN BENITO DE PALERMO EN ESPAÑA
}

\section{Saint Benedict of Palermo in Spain}

\section{Bernard VINCENT}

Escuela de Altos Estudios en Ciencias Sociales, París

Correo-e: bernard.vincent@ehess.fr

RESUMEN: Entre las devociones a los santos negros, la dedicada a San Benito de Palermo en España ha sido la más fervientemente extendida en los siglos XVII y XviII. Este hijo de esclavos, hermano lego en un convento franciscano, murió en loor de santidad de 1589. Su popularidad, estimulada tanto por la Iglesia como por la Monarquía Hispánica, fue considerable en las comunidades de esclavos y de libertos. Benito fue beatificado en 1743, acontecimiento muy celebrado en muchos lugares de España y canonizado en 1807. Pero la desaparición progresiva de la esclavitud en la península Ibérica y la competencia ejercida por la devoción a otros santos negros provocó la disminución del fervor suscitado por la figura de Benito. Sin embargo, gracias a los esfuerzos de la orden franciscana la devoción al santo siciliano ha perdurado hasta nuestros días, particularmente en Galicia.

Palabras clave: San Benito de Palermo; negros; esclavitud; cofradías; franciscanos.

ABSTRACT: Among the devotions to the black Saints, the one of which Benedict of Palermo was the object in Spain in the 17th and 18th centuries was the most remarkable. Born near Palermo to African slaves, this lay brother of a Sicilian franciscan convent, died in the odor of sanctity in 1589. His immediate popularity, encouraged both by the Church and by the Hispanic monarchy, was considerable within the communities of slaves and free blacks. Benedict was beatified in 1743, event which was followed by numerous celebrations and his eventual canonization in 1807 . The 
fervour which surrounded him fade gradually because of the competition represented by the devotion to other black saints and by the very visible decline of slavery. However, thanks to the efforts of the franciscan order, the worship of Saint Benoît of Palermo continued until our days, particularly in Galicia.

Key words: Saint Benedict of Palermo; Negros; Slavery; Confraternities; Franciscans.

El 4 de abril de 1589 moría en el convento de Santa María de Jesús, ubicado en las afueras de Palermo, fray Benito, miembro de la comunidad franciscana. Dos años más tarde un mercader de la ciudad siciliana, Giovanni Domenico Rubbiano, había ya constituido un dossier sobre la vida, las obras y los milagros de este Benito. El mercader no paró en la última década del siglo xvi y la primera del xvII de intervenir para promocionar la devoción al franciscano siciliano, devoción que se había difundido rápidamente en Palermo.

Benito de San Fradello, nombre debido a su lugar de nacimiento cerca de Mesina en 1526, o Benito de Palermo, nombre que generalmente se le ha dado, pasó toda su vida en Sicilia. Hijo de padres esclavos -su padre era de origen etiope- posiblemente emancipados antes de su nacimiento, fue pastor al servicio del dueño de sus padres. Entró luego en una comunidad de ermitaños fundada por un noble, Jerónimo Lanza. Cuando la comunidad fue disuelta por orden del papa Pío IV, en 1562, Benito fue admitido en la orden franciscana y vivió principalmente en el convento palermitano de Santa María de Jesús, como lego. Ejerció de cocinero de la comunidad, pero su inmensa fama provocó la designación de este analfabeto como prior durante tres años y luego como maestro de novicios. Murió en loor de santidad. Los esfuerzos de sus devotos, Giovanni Domenico Rubbiano a su cabeza, provocaron la instrucción de la Inquisitio super Virtutibus et Miracoli de Benito en 1594.

El Rey Católico no podía ser insensible a la trayectoria y a la fama de un sujeto siciliano, ya que a los ruegos de particulares se sumaba la intervención de los virreyes de la isla, más particularmente Juan Fernández Pacheco, duque de Escalona, virrey entre 1606 y 1610 y autor de cartas al respecto al rey Felipe III. Cuando, en junio de 1607, Rubbiano se dirige al soberano para pedir el traslado del ataúd de Benito desde la sacristía hasta la nave de la iglesia del convento de Santa María de Jesús, la devoción al fraile palermitano se ha difundido ya en la península Ibérica ${ }^{1}$.

Las razones que favorecen la difusión de este fervor no faltan. En primer lugar la presencia de una numerosa población de color negro a la cual estaba directamente

1. Archivo General de Simancas, Estado Sicilia, 1162, 195; vid. Fiume, G.: Il santo moro, I processi di canonizzazione di Benedetto da Palermo (1594-1807). Milán, 2002, pp. 38-39. 
dedicado el mensaje elaborado por los turiferarios de Benito. La trata organizada principalmente por los portugueses desde el África subsahariana alimenta continuamente los puertos de Lisboa y de Lagos a partir de los cuales se hace una redistribución hacia Extremadura, Andalucía y en menor medida otras partes de España. El número de esclavos negros sube a lo largo del siglo xvi y se ha considerado que en 1600 puede ascender de 1.600 a $100.000^{2}$. A estos hay que añadir un número muy difícil de cuantificar de libertos y de descendientes de libertos. La inmensa mayoría de los esclavos y libertos vivía en ciudades y su concentración facilitaba la difusión de la imagen de un ser cuya vida ejemplar constituía un modelo a seguir.

Este modelo estaba poderosamente promovido por la inmensa familia de los franciscanos, la orden religiosa más popular de la catolicidad y particularmente bien implantada en España. Según un censo de 1591 existían únicamente en los territorios de la Corona de Castilla 296 conventos de franciscanos observantes, descalzos o capuchinos que albergaban 4.440 religiosos. Las monjas de la familia franciscana eran todavía más numerosas, 5.714 repartidas entre 153 conventos $^{3}$. Los reinos de Sevilla y Córdoba donde vivían importantes grupos de esclavos y libertos negros poseían 57 conventos franciscanos. Pero veremos que los franciscanos de otras regiones con menor presencia servil, como Galicia, tuvieron un papel muy relevante en la promoción de la figura del fraile palermitano y en la universalidad de su devoción.

La campaña con el objetivo de llevar a Benito a los altares reforzaba los planes y los esfuerzos del Rey y de sus consejeros deseosos de imponer la imagen de la monarquía, campeona del catolicismo frente a todos los demás soberanos y particularmente frente al rey cristianísimo de Francia. La beatificación y la canonización de santos «suyos» constituían pruebas evidentes de la excelencia hispánica. El tiempo de la empresa de Rubbiano y de sus apoyos se inserta totalmente en el gran movimiento cuyo cenit fue la canonización conjunta en 1622 de Teresa de Jesús, Ignacio de Loyola, Francisco Javier e Isidro el Labrador. El acontecimiento fue celebrado con fasto en todos los territorios de la monarquía. Sin embargo no fue aislado. Muchos otros procesos de beatificación o de canonización de santos ibéricos están abiertos y generalmente concluidos durante el primer tercio del siglo xvir. El dominico Ramón de Penyafort fue canonizado en 1600; el franciscano Salvador de Horta en 1606; el dominico Luis Bertrán en 1608; el agustino y arzo-

2. Domínguez Ortiz, A.: La esclavitud en Castilla en la Edad Moderna y otros estudios de marginados, Granada, 2003 (en este volumen está reeditado el artículo pionero publicado en 1952 en los Estudios de Historia Social de España); Stella, A., Histoires d'esclaves dans la péninsule ibérique. París, 2000; Vincent, B.: «La esclavitud en el Mediterráneo occidental (siglos XVI-XVIII)», en Martínez Torres, J. A. (ed.): Circulación e intercambios comerciales en el Mediterráneo y en el Atlántico (siglos XVI, XVII, XVIII). Madrid, 2008, pp. 39-64.

3. Molinié-Bertrand, A.: «Le clergé dans le royaume de Castille à la fin du xvi siècle. Approche cartographique», Revne d'Histoire Economique et Sociale, 1973, pp. 6-53. 
bispo de Valencia, Tomás de Villanueva, y Pascual Bailón, fraile lego franciscano en 1618; el general de la Compañía de Jesús, Francisco de Borja, en 1624. La reina Isabel de Portugal fue canonizada en 1625; Pedro de Alcántara, fundador de los franciscanos descalzos, beatificado en 1627; Pedro Nolasco, fundador de la orden de la Merced, canonizado en 1628, cuando otro mercedario, Ramón Nonato, fue beatificado. A su vez, Juan de Dios fue beatificado en 1630.

Cada una de estas proclamaciones ha sido obtenida tras largos procedimientos que han sido jalonados por múltiples gestiones tanto por parte de la realeza como por la de las órdenes de los candidatos a la santidad. Antes de su canonización en 1622, Ignacio de Loyola había sido beatificado en 1609, Teresa de Ávila en 1614, Francisco Javier en 1619. La causa conducente a la canonización de Ramón de Penyafort había sido abierta ya en 1587, pero las intervenciones de Felipe II en 1594 y de Felipe III en 1598 contribuyeron decisivamente al éxito de 1600 . El camino hacia la canonización de Isabel de Portugal fue también largo y uno de sus episodios fundamentales fue la exhumación en 1612 del cuerpo imputrescible de la reina. El proceso ordinario de Juan de Dios empieza en 1623, el proceso apostólico en 1625, cinco años antes de la beatificación. El del rey Fernando III, que terminó en 1671, fue iniciado en 1629. Vemos que España entera estuvo movilizada: Cataluña más particularmente para Salvador de Horta o Pedro Nolasco, Valencia para Tomás de Villanueva o Luis Bertrán, el País Vasco para Ignacio de Loyola, Navarra para Francisco Javier, Ávila para Teresa, Madrid para Isidro el Labrador, Sevilla para el rey Fernando, Granada para Juan de Dios, etc., y todas las ordenes religiosas: el Carmelo, Merced, Santo Domingo, San Agustín, Compañía de Jesús y naturalmente San Francisco.

La promoción de Benito de Palermo es una manifestación de la ejemplaridad de la orden seráfica. Salvador de Horta, Pedro de Alcántara, Pascual Bailón habían pertenecido, como Benito, a una u otra de sus ramas. La iniciativa palermitana tiene además la virtud de hacer participar a Sicilia del gran movimiento de búsqueda de santidad. Otros ejemplos van en el mismo sentido, que consiste en otorgar en este campo protagonismo al mayor número posible de territorios de la monarquía, en el momento de su mayor extensión, el de la union de las dos coronas hispánica y portuguesa. Uno de ellos es obviamente la canonización de Isabel de Portugal. Pero la beatificación de Luis Bertrán asocia el mundo americano donde el dominico, evangelizador de la Nueva Granada, ha pasado muchos años. Su promoción anuncia en cierta medida la beatificación -en 1668- y la canonización -en 1671de Rosa de Lima, primera santa propiamente americana. Adoptar a Benito tuvo como objeto subrayar el alcance universal de la militancia católica de la monarquía hispánica, a través de santos llegados de todos los horizontes.

La propuesta de Rubbiano coincidía además con una reflexión profunda conducida en el seno de la iglesia católica en cuanto al lugar ocupado por la población de color negro en el plan divino. Ayudaba a resolver ambigüedades nacidas 
en gran parte de la justificación de la esclavitud de los negros como consecuencia de la maldición pronunciada por Noé contra su hijo Cam, culpable de haberle mirado cuando estaba desnudo. Cam había heredado África y sus descendientes estaban condenados a servir a sus hermanos.

Unos de los primeros indicios de valoración de los negros apunta a finales del siglo xIv, con la aparición de un Rey Mago negro en la iconografía o con la presencia de Ifigenia, una princesa etíope, en el catálogo de santos del veneciano Petrus de Natalibus, muerto hacia 1400. El Martyrologium Romanum de Cesare Baronio, publicado en 1586, va más lejos. Este oratoriano, historiador de la Iglesia y cardenal en 1596, introduce varios santos en su obra: Baltasar, el rey mago; Felipe, eunuco de la reina etiope Candace, bautizado por el apóstol Felipe, de quien hereda el nombre; Ifigenia, bautizada por el apóstol y evangelista Mateo; Moisés, bandido arrepentido del siglo IV y luego ermitaño; Elesban, príncipe africano del siglo vi, protector de cristianos. Faltaba todavía una personalidad cuya vida hubiese podido ser comprobada.

Muchos factores se habían pues reunido para que la fama de Benito de Palermo tuviera un eco casi inmediato en España. No hay que olvidar que dos de los capítulos generales de los franciscanos posteriores a su muerte tuvieron lugar en España. En 1593 en Valladolid participaban varios padres sicilianos y entre ellos Bonaventura de Caltagirone, que lo presidió. El de 1606 fue reunido en Toledo y el cronista de la orden, Antonio Daza, que dedica algunas páginas a Benito de Palermo en la cuarta parte de la crónica general del nuestro padre San Francisco $y$ de su apostólica orden, publicada en Valladolid en 1611, estaba presente ${ }^{4}$. En el mismo año de 1606 algunas reliquias de San Benito fueron trasladadas a España. Y la comedia El Santo negro Rosambuco de la ciudad de Palermo, muy inspirada en la vida del santo, escrita por Lope de Vega a más tardar en 1607 y quizás ya en 1604. ¿Cómo y cuándo el dramaturgo fue informado? No cabe duda de todas formas de que los años 1606-1608 constituyen un episodio clave de la difusión de la figura del santo negro en España.

El teatro ha sido uno de los principales vectores de su propagación. Los negros estaban muy presentes en las obras del siglo XVI, pero respondían a un estereotipo cuyos elementos burlescos, como el uso de una lengua castellana deformada, eran dominantes. Los primeros personajes negros o mulatos de Lope de Vega siguen este modelo (en Las comendadoras de Córdoba de 1596, donde una de las esclavas se llama Sicilia, El amante agradecido de 1602, El arenal de Sevilla de 1603). Todavía la Lucrecia del Santo negro Rosambuco corresponde al estereotipo.

4. Fiume, G.: «St. Benedict the Moor: from Sicily to the New World», en Cormarck, M. (ed.): Saints and their Cults in the Atlantic World. Charleston, 2007, pp. 30-31. 
Si embargo, el «Fénix» impuso el personaje del santo negro que terminó por constituir un papel de reparto, de género. En el siglo Xvir estos personajes fueron muy habituales en las comedias de santos. Entre 1599 y 1603, Lope crea en El negro del mejor amo la figura del santo negro. El principal protagonista, Antiobo de Cerdeña, pertenece innegablemente al mundo de la ficción. Pero ha nacido en una isla del Mediterráneo occidental y por otra parte Antiobo es hijo de Sofonisba, princesa negra y de Dulimán, príncipe blanco cuyos nombres y algunas características hacen pensar en Ifigenia y en Dunaan, el rey enemigo de Elesban. Lope pudo haber estado muy atento a la emergencia de santos negros, apócrifos o no 5 .

Eligió desarrollar el tema haciendo de Benito el personaje central de otra comedia, pero apartándose del relato hagiográfico que él probablemente conocía. En la primera jornada Benito es Rosambuco, un famoso corsario al servicio de los otomanos. Es cautivado por Pedro Portocarrero que le da al conde Alba de Liste, virrey de Sicilia. En seguida el virrey le ofrece a Lesbio, alguacil mayor. Rosambuco se presenta como un príncipe etiope caído al servicio de la Sublime Puerta y profesando la fe musulmana. Pero conducido a un oratorio donde es testigo de un milagro operado por San Benito de Nursia, pide ser bautizado con el nombre del santo. Las dos últimas jornadas son más próximas a los escritos relativos al santo palermitano que estaban circulando. Después de una aparición de San Francisco durante un sueño, Benito entra en el convento franciscano de Jesús del Monte (o Santa María de Jesús), ejerce la responsabilidad de prior, realiza numerosos milagros y muere en loor de santidad.

Sería muy interesante saber dónde fue representada la comedia y cuáles fueron sus públicos. Pero no cabe duda de que tuvo éxito. Y a continuación la comedia de santos prosperó. Así, en la obra de Felipe Godínez San Mateo en Etiopia, datada en 1635, Felipe el eunuco de la reina Candace e Ifigenia están presentes. El héroe de $E l$ esclavo más dichoso, escrita en 1641 por Rodríguez Álvarez Pacheco, un portugués afincado en Granada, es Antonio de Noto, otro negro franciscano. Y Moisés, el bandido hecho ermitaño, es el protagonista principal de El Negro más prodigioso, redactado por Juan Bautista Diamante. Constatamos que este autor, un año después de haber escrito su comedia (1675), redactó una vida Vida prodigiosa del venerable siervo de Dios Fray Martín de Porres, natural de Lima, de la Tercera orden de Nuestro Padre Santo Domingo, el santo negro peruano muerto en 1639. Pero el más popular de todos en el siglo xvir fue Benito de Palermo, que inspiró a Luis Vélez de Guevara otra comedia titulada El negro del serafín datada de 1643 y muy deudora de Lope.

5. Encontramos innumerables informaciones y análisis sobre las comedias de santos en Martínez López, E.: Tablero de Ajedrez. París, 1998 y en Fra Molinero, B.: La imagen de los negros en el teatro del Siglo de Oro. Madrid, 1995. Ver también Weber de Kurlat, F.: «El tipo negro en el teatro de Lope de Vega: Tradición y creación», Nueva Revista de Filología Hispánica, XIX, 1970, pp. 337-359. 
Podemos medir el fervor dedicado a Benito gracias a la importancia del movimiento confraternal en la población de color negro. No es un azar si Lope de Vega hace decir a la negra Lucrecia en El Santo Negro Rosambuco de la ciudad de Palermo «Turaro (todos los) neglo hecemos confraria al Santo Neglo». Un mínimo de veintiseis cofradías de negros han sido creadas en España entre finales del siglo XIV y mediados del siglo XVIII ${ }^{6}$. Es significativo que siete de ellas lleven el nombre del santo palermitano, las más de las veces añadido durante el siglo XVII a una invocación anterior, siendo la más frecuente la de Nuestra Señora del Rosario. La adopción del nombre de Benito traduce el progreso de la devoción en Cádiz (dos cofradías) en el Puerto de Santa María, en Gibraltar, en Granada, en Jaén. La única bajo el patronazgo de Benito a secas es la última fundada, la de Madrid, creada en 1747, inmediatamente después de la beatificación ocurrida en 1743. Los demás santos están ausentes de esta evolución con la excepción de Ifigenia, que acompaña Benito en la advocación de una de las cofradías gaditanas, la de Nuestra Señora de la Salud y San Benito y Santa Ifigenia. Una investigación queda pendiente para fechar la introducción de santos negros en los nombres de las cofradías y así precisar las condiciones del desarrollo del fervor que les rodea.

La cofradía de negros más antigua de España, la de la Piedad y Nuestra Señora de los Ángeles de Sevilla, jamás ha introducido jamás el nombre de Benito en su título. Pero el inventario de bienes, establecido el 1 de marzo de 1676, es revelador de la veneración tributada al santo. Ese día un nuevo mayordomo se hace responsable de los elementos del patrimonio de la cofradía. En la lista encontramos las estatuas de Santa María de los Ángeles, de Cristo, de San Benito de Palermo y de otra Virgen de los Ángeles 7 . Una procesión, detrás de la estatua de Benito fue organizada en 1807, a raíz de la canonización, desde la capilla de nuestra Señora de los Ángeles hasta el convento de los franciscanos. Sabemos, gracias al antropólogo Isidoro Moreno, que teniendo al principio solamente cabeza y manos la estatua figuraba en un retablo donde dos cuadros representaban a Elesban e Ifigenia. Una reforma de la capilla realizada a partir de 1964 hizo desaparecer el retablo. Salvada, la estatua de San Benito fue modificada: ahora tiene un cuerpo entero y está colocada en una consola.

Otras cofradías de morenos han sido dueñas con toda probabilidad de estatuas o cuadros que representan al santo franciscano, ya en el siglo xvir. Hoy todavía se conserva una estatua de San Benito de Palermo -y otra de Santa Ifigenia- en la iglesia parroquial de Nuestra Señora del Rosario en Cádiz. Obra sin duda de

6. Vincent, B.: «Pour une histoire des confréries de Noirs», en Dompnier, B. y Vismara, P. (eds.): Confréries et dévotions dans la catholicité moderne (mi XVI-début XIX siècle). Roma, 2008, pp. 243-260.

7. Moreno, I.: La antigua hermandad de los negros de Sevilla, etnicidad, poder y sociedad en 600 años de Historia. Sevilla, 1997, p. 120. 
mediados del xvir, pertenece a la cofradía de Nuestra Señora de la Salud y San Benito y Santa Ifigenia. Pero la pobreza generalizada de las cofradías y la desaparición de muchas de ellas han provocado la perdida de la mayoría de las obras. El ejemplo de la destrucción del retablo de la capilla de Nuestra Señora de los Ángeles de Sevilla donde sin embargo la cofradía de los Negritos (según su nombre popular) existió sin discontinuidad, es a este respecto muy significativa.

En la iglesia de San Antonio de Padua de Sevilla hay un retablo con un San Benito de Palermo. Está atribuido a Felipe de Ribas, activo en la ciudad del Guadalquivir en los años 1640. El Museo Nacional de Escultura de Valladolid posee un San Benito de principios del siglo xvirı. Procede del convento de San Diego de los Franciscanos Descalzos de la misma ciudad. Según la descripción del inventario del museo "posiblemente algún sirviente negro sirviera de modelo para la juvenil cabeza, vuelta hacia el crucifijo que sostendría con su mano izquierda, mientras que en la derecha encierra su atributo característico: un corazón del que manan siete gotas de sangre, en referencia a las virtudes -las tres teologales y las cuatro cardinales- que le adornaron». El convento de clarisas de la Encarnación de Granada conserva una estatua de San Benito cuyo autor es José de Mora, uno de los mejores escultores de la escuela andaluza, discípulo de Alonso Cano. La obra debe ser de finales del siglo Xvir. En el museo de Agen, en el suroeste francés, se encuentra una estatuilla de madera representando a San Benito atribuida a Alonso Cano. No tenemos ninguna prueba formal de la autoría del gran artista granadino, pero la obra, de excelente factura, ha salido evidentemente de un buen taller. El Minneapolis Institute of Art posee un San Benito de Palermo realizado hacia 1734 por el escultor sevillano José Montes de Oca y León, que se formó en el taller de Pedro Roldán. Otras obras que representan al santo probablemente también de finales del siglo XviI o principios del XviıI, una en la iglesia San Pedro el Real de Córdoba, otra en la iglesia parroquial de Cañete de las Torres, al este de Córdoba, testimonian la difusión de la devoción a San Benito en Andalucía. Estas dos últimas estatuas figuraban en las procesiones más importantes del calendario litúrgico, por ejemplo en la del Corpus Christi. En Cañete, San Benito estaba acompañado por dos o tres negros, en Córdoba el palermitano precedía a la estatua de San Francisco.

La iconografía es, a través de estas obras, casi siempre la misma. Benito, como en el ejemplar del museo de Valladolid, vestido con el hábito franciscano lleva en la mano derecha una cruz y en la mano izquierda un corazón, expresión del fuego del amor divino. En un compendio redactado a mediados del siglo XVIII, el franciscano Francisco Antonio Castellano sitúa el origen de esta representación en uno de los muy numerosos milagros atribuidos al santo. Cuenta el episodio de una procesión del Corpus Christi en Palermo. El arzobispo había pedido que Benito llevara la cruz. El rostro del franciscano en contemplación se llenó pronto de brillantes lágrimas que iluminaban a todas las personas presentes. Castellano insiste en su 
dedicatoria «todo llamas fue nuestro Santo Negro. Prueba de esta verdad fue el milagro repetido de salir de su lugar el corazón y hacer asiento en el rostro de nuestro glorioso Santo; exhalando encendidas llamas, con que manifestaba de su corazón los incendios y abrasaba en fuego de amor Divino a quantas ilustraba con sus hermosos rayos» ${ }^{8}$. El autor precisaba que ahí radicaba la razón de pintar o dibujar el santo negro con el corazón en la mano. Esta representación no está ausente de otros territorios como la Nueva España, pero no es nunca dominante como en España. Se prefiere al santo llevando en brazos, a la manera de Antonio de Padua, al niño Jesús, muy frecuente en Brasil o el santo arrodillado flagelándose como en Granada (Nicaragua) o al santo del milagro de las inmundicias transformadas en flores en la iglesia de Nuestra Señora de Gracia de Lisboa.

La presencia de Benito de Palermo en Sevilla, Granada, Córdoba, Cádiz, Cañete de las Torres, etc. traduce la estrecha relación existente entre el santo y las comunidades de negros en Andalucía. Sin embargo estas estaban las más de las veces en retroceso desde mediados del siglo XviI porque la trata africana en dirección a Europa estaba decayendo. El mantenimiento del fervor popular hacia el santo palermitano dependía en gran parte de la capacidad de los franciscanos de promover su figura. Uno de los testimonios más elocuentes de esta tarea es el cuadro realizado hacia 1720 por Lucas Valdés, el hijo de Juan de Valdés Leal, para el convento sevillano de la orden. El tema, la alegoría de la institución de la Orden Tercera, es pretexto para la demostración de la excelencia franciscana, con catorce santos franciscanos rodeando a San Francisco y reagrupados en tres rangos. Entre ellos Antonio de Padua, Isabel de Portugal, Conrado de Plasencia y Benito de Palermo. Según Vittorio Marabito, el modelo del retrato de Benito, visto de perfil, sería el busto realizado en 1611 para el convento de Santa María de Jesús, donde el santo había muerto9. No cabe duda de que a principios del siglo XviII los esfuerzos de la orden seráfica habían conseguido su objetivo. La afición a la figura de Benito era patente en medios muy diversos. Es interesante constatar que la cofradía de «los Negritos» de Sevilla no ha desaparecido con la disminución progresiva del número de cofrades de color negro a lo largo de los siglos XVIII y XIX ${ }^{10}$. El relevo ha sido asumido por cofrades del color blanco, cada vez más numerosos. La beatificación proclamada en 1743 y la canonización en 1807 han sido ocasión de una serie de manifestaciones revelando la difusión de

8. Castellano, F. A.: Compendio de la heroica y maravillosa vida, virtudes excelentes y prodigiosos milagros del mejor Negro...el Beato Benito de Palerma... llamado el Santo Negro. Murcia, 1752.

9. Morabito, V.: «San Bendetto il Moro de Palermo, prottetore degli africani di Siviglia, della peninsola iberica e d'America Latina», en Ares Queija, B. y Alessandro, S. (eds.): Negros mulatos, zambaigos. Sevilla, 2000, pp. 223-273. Ver particularmente pp. 234-237.

10. Moreno, op. cit. pp. 142-148. 
la devoción a San Benito en muchas partes de España donde la población negra era poca o aún desconocida.

En este marco se han multiplicado los escritos (hagiografías, novenas, etc.) exaltando las virtudes del santo y a menudo acompañados de grabados que han podido servir de modelos a estampitas, asegurando la popularidad de Benito. Esta literatura fue abundante en las décadas centrales del siglo xvin, y a veces fomentada por la rivalidad entre las ramas del franciscanismo, deseosas cada una de reivindicar la figura del palermitano. Ya en 1744, un año justo después de la beatificación, el descalzo Antonio Vicente de Madrid redacta El Negro más prodigioso: Vida del Beato Benito de San Philadelphia o de Palermo, Llamado el Santo Negro y defensa apologética de su familia..., objeto de una inmediata réplica por parte de un observante anónimo, estableciendo el catálogo de los errores cometidos por Vicente de Madrid ${ }^{11}$. Las críticas están retomadas por el observante Diego Álvarez, miembro de la comunidad de Alcalá de Henares, en un documento impreso en $1747^{12}$. Antonio Vicente de Madrid contesta a sus detractores en una nueva versión amplificada de su vida en 1758. Dos hagiografías más ven la luz antes de esta reedición, la de Francisco Antonio Castellano, predicador en el convento de la Purísima Concepción de Mula (Murcia) en 1752 y la del franciscano de Girona Jaume Aixala, autor en 1757 de la única escrita en catalán ${ }^{13}$. A estos textos se añaden múltiples novenas. Una primera es objeto de una reimpresión en Murcia en 1749 -la fecha de la impresión original es desconocida- y su autor es «un devoto de el santo, el mínimo entre sus Menores Hermanos»; otra es redactada el mismo año por Silvestre Vega, bibliotecario del convento de franciscanos San Juan de los Reyes de Toledo ${ }^{14}$. La «Novena al más libre rendido esclavo de Jesús y María... el beato Benito de Palermo», de fecha desconocida, publicada en Madrid, es debida a la pluma de Francisco de Buendía, predicador y procurador de la provincia de la purísima concepción de religiosos franciscanos descalzos en Castilla la Nueva. Notamos que el autor de la novena murciana califica a Benito de «hijo de la más estrecha Observancia de Nuestro Padre Francisco de la Reforma

11. La crítica de la obra de Antonio Vicente de Madrid ha sido así mismo objeto de una respuesta probablemente ya en 1744 . Ver Copia de una carta y su satisfactoria respuesta.

12. Álvarez, D.: Sombra ilustrada con la razón, demostración, admirable vida, virtudes y milagros de el beato Benito de San Fradello conocido como el Santo negro de Palermo. Alcalá de Henares, 1747.

13. Aixala i Gassol, J.: Vida portentosa, heroicas virtuts y estupendos miracles del molt insigne sicilia lo beato Benet de Palermo, dit vulgarment lo santo negro. Girona, 1757.

14. Vega, S.: Sagrada novena de el mas hermoso negro, precioso lunar, que colocado en la mas principal parte de el Cuerpo Mystico de la Religion Serafica le añade especial belleza a su hermosura, San Benito di Palermo, vulgarmente llamado el Santo negro. Madrid, 1749. 
de Sicilia». Retendremos del conjunto de iniciativas que, si la familia franciscana está dividida, el consenso alrededor de la figura de San Benito es absoluto.

La obra de José Benegasi y Luján Vida del portentoso negro San Benito de Palermo intenta reconciliar las dos ramas de la orden seráfica ${ }^{15}$. Lleva un grabado de Donato Hernández que representa al santo acompañado por dos ángeles llevando uno el hábito de los reformados, y el otro el de los recoletos. El texto del mismo grabado precisa:

\section{De estos dos mantos uno \\ Trajo Benito \\ Ponganle el que gustaren \\ Los Eruditos}

El libro tuvo un notable eco como lo indican sus reediciones en 1763 y 1779. Su autor es un personaje aparentemente sin relación estrecha con los franciscanos, razón quizás por la cual la polémica interna a la orden le parece totalmente vana. Benegasi y Luján, señor de los Terreros y Valdecielos y regidor de la ciudad andaluza de Loja, era patrón de una capilla del monasterio de Jerónimos de Madrid, fundada por su antepasada Ana de Luján. Y si el padre Alonso Lorente, predicador del convento madrileño de San Francisco, le animó a escribir su libro, este fue aprobado por el cisterciense Isidoro Francisco Andrés y fue objeto de un entusiasta comentario del censor, el carmelita Juan de la Concepción. Además Benegasi dedica su obra al Marqués de Estepa, gentilhombre de cámara del Rey. Su ejemplo enseña que los devotos a San Benito de Palermo pueden beneficiarse de muchos prestigiosos apoyos. Francisco Antonio Castellano ofrece su libro a José Antonio de Llamas, marqués de Mena Hermosa y gobernador de la plaza de Callao. El pedido de ayuda formulado por los franciscanos descalzos de Toledo, deseosos de organizar en 1744 una fiesta en honor al nuevo beato, es respaldado por el regidor Ramón de la Palma y por el jurado Joaquín García de Madrid ${ }^{16}$. En 1762 el obispo de Barcelona, Asensio Sales, concede cuarenta días de indulgencia a quien rece delante de la imagen del santo que grabó Francisco Boix ${ }^{17}$. En 1769 el arzobispo de Granada, Pedro Antonio Barroeta y Ángel, y el obispo de Guadix, Francisco Alejandro Bocanegra y Gibaja, conceden cien días de indulgencia a los fieles que recen delante de la imagen de San Benito del convento de San Francisco de Guadix. De hecho, la devoción al santo palermitano llegó a ser muy difundida en los años que siguen inmediatamente la beatificación. Así, en la parroquia San

15. Benegasi y Luján, J. J.: Vida del portentoso negro, San Benito de Palermo, descripta en seis cantos. Madrid, 1750.

16. Archivos municipales de Toledo, Festejos 1136. Documento del 12/II/1744.

17. Calcografía de Madrid, Colección Antonio Correa, caja 48, AC 9701. 
Salvador de Valladolid donde se da un abogado a los bautizados aparece entre ellos por primera vez Benito de Palermo en 1744. Y de los 273 bautizados entre 1749 y 1752, 13 tienen como abogado al beato palermitano, casi el 5\% ${ }^{18}$. Pero desaparece brutalmente, victima de la fama del vallisoletano Pedro Regalado, igualmente franciscano y canonizado en 1746. Así se mide a la vez tanto la importancia del fervor hacia Benito de Palermo como su fragilidad.

El conjunto de los textos que he citado buscan fijar una representación definitiva del santo. Su condición de esclavo admitida sin reparo en el siglo XviI por la literatura heredada de la crónica franciscana de Antonio Daza es posteriormente cuestionada cuando la presencia de esclavos de color negro está desapareciendo ${ }^{19}$. La obra del canónigo de Palermo, Pedro de Mataplanes, publicada en Madrid en 1702, que la niega, tuvo mucha influencia ${ }^{20}$. Siguiéndole, los autores españoles de mediados del siglo Xvin insisten casi siempre sobre la libertad de que gozaba Diana Larcan, la madre de Benito. Su condición, transmitida por su madre, hacía de Benito un hombre libre. Y la santidad permite rebasar el color de la piel que no puede ser ignorado. Esta postura ha servido a asegurar una más profunda propagación del culto a San Benito fuera del mundo de los esclavos. Los distintos autores hacen variaciones a partir de la paradoja a sus ojos de la elección divina de un Negro. José Benegasi empieza su poema con este tema:

Escuchenme la vida

De un negro Santo

Escuchenla, y aprendan

Los hombres blancos

Que los no buenos

Para Dios, aunque blancos

Siempre son negros

Y según la novena publicada en Murcia en 1749, el fiel solicita la intercesión del «Negro divino... Blanco de los cariños de todo un dios». En estas condiciones los escritos tienden a limitar el relato de la vida del santo a su estancia en el convento de Santa María de Jesús. Insisten sobre la humildad del personaje alejada del carácter altivo y violento que tenía anteriormente a su conversión, tal como la habían pintado los autores de obras profanas del xviI, particularmente

18. Debo estos datos a la generosidad de Lourdes Amigo, autora de un trabajo sobre Pedro Regalado.

19. Daza, A.: Quarta parte de la Cronica general del Nuestro Padre San Francisco y su Apostolica Orden. Valladolid, 1611.

20. Mataplanes, P.: Vida de Fray Benito de S. Fradelo, religioso recoleto de la Orden de S. Francisco, comúnmente nombrado el Santo Negro de Palermo. Madrid, 1702. 
en las comedias cuyo contenido está vehementemente condenado. Una vez más Benagasi da el tono,
Que San Benito
Fue esclavo solamente
De Jesucristo
Pero aunque libre
No libre de comedias
Que lo esclavicen
De un tal portocarrero
Le hacen esclavo
Pero es una comedia
Todo aquel passo
Que en los ingenios
Suelen ser las mentiras
Mas que los versos

Estos versos apuntan a las comedias de Lope de Vega y Vélez de Guevara que hacen de Rosambuco-Benito un esclavo de don Pedro Portocarrero. La alusión concierne más particularmente el «ingenioso» Lope. Y es interesante constatar que fray Juan de la Concepción, censor del poema, es todavía más virulento acerca del tratamiento reservado por el teatro a Benito. «Porque» dice «hasta ahora en nuestra España, han intentado copiarle (S. Benito) en la Prosa, y han conseguido desfigurarlo totalmente en el Verso. Una comedia hai escrita del Santo que tiene mas mentiras que scenas. Alli se hallan Vandos fingidos, Milagros falsos, Travesuras indignas, Rodamontadas quiméricas». Es probable que esta campaña tratando de imponer una imagen depurada del santo siciliano provocase la rarefacción de funciones de comedias de santos negros.

A la inversa, la representación tradicional de Benito por los artistas no planteaba problemas. La estatua presente en el altar de la iglesia del convento del carmelo de Pastrana es la de Benito teniendo en su mano izquierda el corazón del amor divino. Obra probablemente de José Salvador Carmona, realizada en la segunda mitad del siglo xviII, estaba destinada a la iglesia del convento franciscano de Aranjuez ${ }^{21}$. Fue trasladada a Pastrana en 1855, cuando los franciscanos se instalaron en el convento de donde habían sido expulsados los carmelitas cuando la desamortización de 1836. Así mismo, las imágenes de San Francisco de Mula de 1752 o de San Francisco de Guadix son las clásicas del santo con la cruz en una mano y el corazón en la otra. La de Mula es obra del grabador oriolano Pedro de Paredes y el texto que figura

21. Museos, museo de arte sacro $u$ de ciencias naturales, Franciscanos, Pastrana (Guadalajara). Ávila, 2005. 
en ella dice «San Benito de Palermo exemplarissimo en milagros especialmente de males de corazón cosechas de seda y de partos difíciles».

En este contexto se constituyó la última cofradía de San Benito de Palermo creada en España. En sus ordenanzas aprobadas por el Consejo de Gobernación de Toledo el 16 de febrero de 1747 se indica que «hicieron y fundaron los negros una hermandad y cofradía en el Convento de Nuestro Padre San Francisco de esta Corte» ${ }^{22}$. La admisión en la cofradía está regulada por el segundo de los doce capítulos de las ordenanzas. Se precisa que los candidatos «sean cristianos del color del Santo, que sepan la doctrina cristiana, de buena vida y costumbres, modestos, quietos, pacíficos, y sosegados, sin nota de escandalosos por blasfemos, maldicientes o jugadores, embriaguez, lascivia o latrocinio, el que no tuviere dichas calidades podra ser admitido sea soltero o casado, libre o esclavo, pero estos con licencia inscriptis y firmada de sus amos y no de otra suerte. Con dichas calidades podran ser admitidos también los blancos si la junta de oficiales los admitieren pareciendoles conveniente». La lista inicial de cofrades comprende veinticuatro personas, en su mayoría probablemente libres por llevar nombres y apellidos y siendo, según palabras del primer capítulo, «por lo regular pobres todos los negros questamos por estos paises». No sabemos cuál ha sido la duración de vida de esta cofradía, pero podemos inferir del mismo texto de las ordenanzas que por dificultades encontradas no ha pudo prosperar.

En 1807 Pío VII canonizó conjuntamente a cuatro santos franciscanos: Santa Ángela, Santa Coleta, Santa Jacinta y Santo Benito de Palermo. Una estampa del zaragozano José Gabriel de la Fuente ilustra el acontecimiento representando arrodillados a los cuatro santos ${ }^{23}$. Pero en el convento de San Francisco de Zaragoza está una estatua del santo palermitano con la cruz y el corazón en las manos. La iconografía no cambia y no cambiará. Sin embargo, el fervor a lo largo del siglo xix no es el de los tiempos anteriores. Los escasos testimonios vienen preferentemente de territorios hasta la época poco pródigos. Unos Gozos a San Benito de Palermo publicados en Valencia en 1871 con un grabado representando al palermitano con un crucifijo en la mano derecha, pero la mano izquierda libre; otros Gozos a San Benito de Palermo venerado en el convento de San Diego del lugar de Alfara, Alfara del Patriarca al norte de Valencia; aún Gozos de San Benito de Palermo que se venera en el convento de San Francisco de Asis de Palma para todos sus devotos y bienhechores, editado en Palma de Mallorca. Estos dos últimos son también de la segunda mitad del siglo XIX.

Existe también una Devota novena del glorioso San Benito de Palermo que se venera en la iglesia parroquial de Redondela, publicada en Pontevedra en 1860.

22. Archivo Histórico Nacional de Madrid, Consejos, libro 5496/1.

23. Calcografía de Madrid, Colección Antonio Correa, caja 42, AC 9022. 
No es un azar, porque ya a finales del siglo XVIII y en los primeros años del XIX varios conventos franciscanos de Galicia se han dotado de estatuas representando a San Benito. La de la iglesia de San Francisco de Santiago de Compostela ha sido ejecutada por José Ferreiro, escultor nacido en Noya, autor también de la estatua del convento franciscano del $\mathrm{Ferrol}^{24}$. Benito lleva cruz y corazón. Otras obras han sido igualmente realizadas a principios del siglo XIX en San Francisco de Canedo, al este de Pontevedra y en la parroquia de Baya de Arealonga que depende de Villagarcia de Arousa ${ }^{25}$.

Nos podemos preguntar si la de San Francisco de Noya, la ciudad de Ferreiro, no pertenece al mismo grupo. Todavía existen las estatuas de Xunqueira de Ambia al sureste de Orense, de Grandes de Salme en Asturias pero con proximidad a Lugo y obviamente de Rondadela. Además, tres romerías se celebran cada año en honor a Benito de Palermo, una en San Pedro de Angoares (Ponteareas) al sur de Pontevedra, y las demás en San Benito de Lores y en Cobas, pueblos de la comarca del Salnés al noroeste de Pontevedra. Así hoy todavía Galicia, principalmente la zona costera, lleva una relación estrecha con el santo negro. Es una situación paradójica, porque la población de color negro ha estado casi ausente de una región que ha prácticamente ha ignorado la esclavitud en la época moderna. Se ha producido a lo largo de los siglos un fenómeno de inversión, pues Andalucía, tierra de mano de obra servil, hasta el XVII incluso, ha progresivamente olvidado a Benito de Palermo. No en todas partes, por ejemplo al palermitano se le tiene mucha devoción en la iglesia de San Francisco de Priego (Córdoba), donde la estatua recibe todavía muchos exvotos, sobre todo de estudiantes en vísperas de exámenes ${ }^{26}$. Pero Martín de Porres, el santo peruano, perteneciente a la orden dominica y teniendo características muy próximas a las de Benito, le hace mucha competencia. En la sevillana capilla de los Ángeles, sede de la cofradía de los Negritos, las estatuas de los dos santos están a pocos metros una de otra.

Queda por hacer un inventario de todos los lugares de España donde se rindió en algún momento culto al palermitano y luego intentar explicar las evoluciones. En el caso de Galicia han ciertamente tenido peso los esfuerzos de los franciscanos. Pero podemos también emitir la hipótesis de una influencia de la emigración gallega al Nuevo Mundo, donde los santos negros son extremadamente populares.

24. Agradezco a Enríque Martínez Rodríguez sus numerosas indicaciones y en particular la identificación de José Ferreiro.

25. La estatua de San Francisco de Canedo se conserva hoy en la parroquia de San Pedro de Angoares.

26. Debo a esta información, como las relativas a Guadix, a Miguel Luis López-Guadalupe. 
BERNARD VINCENT

SAN BENITO DE PALERMO EN ESPAÑA

\section{BiBLIOGRAFÍA}

Áixala I Gassol, J.: Vida portentosa, heroicas virtuts y estupendos miracles del molt insigne sicilia lo beato Benet de Palermo, dit vulgarment lo santo negro. Girona, 1757.

Álvarez, D.: Sombra ilustrada con la razón, demostración, admirable vida, virtudes y milagros de el beato Benito de San Fradello conocido como el Santo negro de Palermo. Alcalá de Henares, 1747.

Castellano, F. A.: Compendio de la heroica y maravillosa vida, virtudes excelentes y prodigiosos milagros del mejor Negro... el Beato Benito de Palerma... Ilamado el Santo Negro. Murcia, 1752.

Benegasi y Luján, J. J.: Vida del portentoso negro, San Benito de Palermo, descripta en seis cantos. Madrid, 1750.

DAZA, A.: Quarta parte de la Crónica general del Nuestro Padre San Francisco y su Apostólica Orden. Valladolid, 1611.

Domínguez OrTiz, A.: La esclavitud en Castilla en la Edad Moderna y otros estudios de marginados. Granada, Editorial Comares, 2003.

Fiume, G.: «St Benedict the Moor: from Sicily to the New World», Saints and their Cults in the Atlantic World. Margaret Cormack ed. Charleston, 2007.

Fra Molinero, B.: La imagen de los negros en el teatro del Siglo de Oro. Madrid, 1995.

Martínez López, E.: Tablero de ajedrez. París, Fundación Gulbenkian, 1998.

Mataplanes, P. de: Vida de Fray Benito de S. Fradelo, religioso recoleto de la Orden de S. Francisco, comúnmente nombrado el Santo Negro de Palermo. Madrid, 1702.

Molinié-Bertrand, A.: «Le clergé dans le royaume de Castille à la fin du xve siècle. Approche cartographique», Revue d'Histoire Économique et Sociale, 1973, pp. 6-53.

Morabito, V.: «San Benedetto il Moro di Palermo, prottetore degli africani di Siviglia, della penisola iberica e d'America latina», Negros, mulatos, zambaigos, ArEs QueIJA, B. y STELlA, A. eds. Sevilla, 2000, pp. 223-273.

MoReno, I.: La antigua hermandad de los negros de Sevilla, etnicidad, poder y sociedad en 600 años de Historia. Sevilla, 1997.

Museos, Museo de arte sacro y de ciencias naturales. Franciscanos, Pastrana (Guadalajara). Ávila, 2005.

Stella, A.: Histoires d'esclaves dans la péninsule ibérique. Paris, E.H.E.S.S., 2000.

VEGA, S.: Sagrada novena de el mas hermoso negro, precioso lunar, que colocado en la mas principal parte de el Cuerpo Mystico de la Religion Serafica le añade especial belleza a su hermosura, San Benito di Palermo, vulgarmente llamado el Santo negro. Madrid, 1749.

VINCENT, B.: «La esclavitud en el Mediterráneo occidental (siglos XVI-XVIII)», Circulación e intercambios comerciales en el Mediterráneo y en el Atlántico (siglos XVI, XVII, XVIII). Martínez Torres, J. A. ed. Madrid, C.S.I.C., 2008, pp. 39-64.

VINCENT, B.: «Pour une histoire des confréries de Noirs», Confréries et dévotions dans la catholicité moderne ( $m i$ XVIe - debut XIXe siècle). DOMPNIER, B. y VismarA, P. eds. Roma, Ecole Française de Rome, 2008, pp. 243-260.

Vicente De MAdRID, A.: El negro más prodigioso: Vida del beato Benito de San Philadelphia o de Palermo, llamado el Santo Negro y defensa apologética de su familia. Madrid, 1744

Weber DE Kurlat, F.: «El tipo negro en el teatro de Lope de Vega: tradición y creación», Nueva Revista de Filología Hispánica, XIX, 1970, pp. 337-359. 